\title{
Drug utilization pattern and selected biochemical parameters in pre- and post-hemodialysis state in the end stage renal disease patients: a cross sectional study at a tertiary care hospital
}

\author{
S. P. Gokulraj ${ }^{1}$, Surendra Kumar Bouddh ${ }^{2}$, J. Rajesh ${ }^{3}$
}

\begin{abstract}
${ }^{1}$ MBBS student, ${ }^{3}$ Department of Nephrology, Dhanalakshmi Srinivasan Medical College and Hospital, Perambalur, Tamil Nadu, India

${ }^{2}$ Department of Pharmacology, Govt. Medical College, Datia, Madhya Pradesh, India
\end{abstract}

Received: 15 July 2019

Revised: 06 August 2019

Accepted: 07 August 2019

\section{*Correspondence to:}

Dr. Surendra Kumar Bouddh, Email: sk85bouddh@gmail.com

Copyright: () the author(s), publisher and licensee Medip Academy. This is an openaccess article distributed under the terms of the Creative Commons Attribution NonCommercial License, which permits unrestricted noncommercial use, distribution, and reproduction in any medium, provided the original work is properly cited.

\begin{abstract}
Background: Chronic kidney disease can progress to end-stage kidney failure (ESRD), which is fatal without artificial filtering (dialysis) or a kidney transplant.

Methods: The ESRD patients of either gender age $>18$ years who were diagnosed by nephrologist as ESRD and are on haemodialysis regularly included for the study.

Results: The blood urea, serum creatinine, phosphorous, potassium levels were reduced significantly in post - haemodialysis condition, but, there was not much weight reduction after haemodialysis. Serum albumin, serum sodium and blood haemoglobin levels were almost unchanged in post - haemodialysis state. There was no significant difference between the pre and post haemodialysis parameters- serum $\mathrm{Na}+$ serum albumin and blood hemoglobulin. Out of 75 ESRD patients, almost all patients 74 (98.7\%) prescribed tablet Livogen, 73 (97.3\%) patients given Inj. EPO, 55 (73.3\%) tab Nicardia, 54 (76\%) tab Sodamint, $43(57.3 \%)$ capsule Alpha D3, 40 (53.3\%) tab Shelcal. While between $12(16 \%)$ to 20 (26\%) patients prescribed tab Nodosis, tab Metoprolol, tab Febuget, tab Ecosprin, and tab Rantac. Only 1 (1.3\%) to 9 (12\%) patients received tablet Augmentin, tab Arkamine, tab Carvedilol, tab Para 500, tab Atorvas, Human mixtard, tab Calcicard, tab Minipress XL, tab Dytor, and tab Clopilet.

Conclusions: The available two models of treatment, i.e., haemodialysis and poly pharmacy at hospital setup to face the challenges associated with the ESRD, and even outcome after application of both these two models of therapies did not provide optimal normal healthy life status to ESRD patients.
\end{abstract}

Keywords: ESRD, Haemodialysis, Poly-pharmacy, Drug utilization pattern

\section{INTRODUCTION}

Chronic kidney disease, also known as chronic kidney failure, is a major health issue in the world. In India, the overall prevalence of chronic kidney disease is $17.2 \%$ which was reported by the SEEK India cohort. Chronic kidney disease (CKD) results from partial or total loss of kidney function. When the kidney function is low, they cannot effectively filter wastes and excess fluid from blood. Adults (41-60 years) and elderly people (60+ years) have more risk to suffer from chronic kidney disease than the other age groups. To stratify the severity of chronic kidney disease the National Kidney Foundation developed criteria as part of its kidney disease outcomes quality initiative (NFKKDOQI ${ }^{\mathrm{TM}}$ ), this stratification considers the estimated glomerular filtration rate (eGFR) as the chief criteria. Chronic kidney disease can progress to end-stage kidney failure, which is fatal without artificial filtering (dialysis) or a kidney transplant. End stage renal disease (ESRD) is the last stage (stage V) of chronic kidney disease, that is, the kidneys are functioning at less than $15 \%$ of their normal capacity. $^{2}$ 
Haemodialysis is the most common medical intervention method to postpone the consequences of the ESRD. A typical haemodialysis schedule is 2 or 3 sessions per week, for 3-5 hours per session. Haemodialysis is essential for the ESRD patient to filter waste, remove extra fluid and to maintain electrolyte balance. ${ }^{3}$

Patients with ESRD are associated with other co-morbid diseases like diabetes mellitus, hypertension, coronary artery diseases and infections adding to the complexity and need for multiple drug therapy, consequently risk of drug interactions, medication dosing errors, and high incidence of adverse drug events, which results in increase morbidity and mortality, as well as an increase in the cost of health care. There is limited evidence on the prescribing trends in ESRD patients from India. ${ }^{4}$

This study offers an insight into the prescribing trends in ESRD patient which can help to identify, evaluate and minimize prescription errors and thereby decrease the burden of the disease.

\section{Objectives}

- To find out drugs utilization pattern in the ESRD patients.

- To compare pre- and post - haemodialysis effects on the biochemical parameters, like blood urea, serum creatinine, serum $\mathrm{Na}+$, serum $\mathrm{K}+$, serum calcium, serum phosphorous, serum albumin, blood hemoglobulin and body weight in the ESRD patients.

\section{METHODS}

\section{Ethical approval}

The study was initiated after getting ethical approval from Institutional Ethics Committee (Human Studies), IECHS.

\section{Study design}

It was a cross sectional study at the tertiary care hospital.

\section{Study population and study location}

ESRD patients who were admitted for haemodialysis in the Department of Nephrology at a tertiary care hospital.

\section{Sample size}

Seventy five (75) ESRD patients.

The minimum sample size to be considered for the study is equal to $\frac{z^{2} \times p(1-p)}{e^{2}}$ where $z=1.96$ for confidence level of $95 \%, e=0.05$ for estimation error of $5 \%$, and $p=0.008$ as the prevalence rate of ESRD patients is $0.8 \%$ which was reported by the SEEK India cohort. ${ }^{1}$
On calculation we get that sample size must be 13 approximately. Since there were many ESRD patients undergoing dialysis at the facility, the sample size was chosen to 75 and also that the data was collected from the case sheets and haemodialysis register without interfering the treatment after obtaining proper approval from Nephrology Department, so there was no wastage of resources.

\section{Inclusion criteria}

ESRD patients of either gender age more than 18 years who were diagnosed by nephrologist as ESRD and are on haemodialysis regularly included for the study.

\section{Exclusion criteria}

The incomplete data of the ESRD patients of either gender age below 18 years excluded from the study.

\section{Informed consent}

Since, it was an observational study, and the data was collected from the case sheets and Haemodialysis register without interfering the treatment after obtaining proper approval from Nephrology Department, so technically, we were not concerned with the ESRD participants directly, thus, no need to take the consent.

\section{Data collection}

The ESRD patient's data like their age, sex, biochemical parameters, as Blood urea, serum creatinine, serum $\mathrm{Na}+$, serum $\mathrm{K}+$, serum calcium, serum phosphorous, serum albumin, blood hemoglobin and drugs being utilized were noted from the patient's case sheet and from the haemodialysis register (pre - and post-haemodialysis) after getting proper permission from the Head of Department of Nephrology. The weight of the patient was measured before and after haemodialysis using standard weighing machine in kilograms. Study participant's data were noted on the prepared data collection sheets accordingly.

\section{Data collection duration}

The data were collected from $1^{\text {st }}$ May, 2018 to $25^{\text {th }}$ August, 2018.

Data was collected in a predesigned proforma sheet (as given in Table 1).

\section{Statistical analysis}

All the data were arranged systematically on Microsoft Excel sheets 2013 and statistical analysis were done by using authentic OpenEpi.info online free available software. We calculated percent, mean value, standard deviation (S.D.), and level of significance ( $p$ value) were calculated by applying two tailed t-test. We had 
estimation error as $5 \%$ and with the confidence level of $95 \%$.

\section{RESULTS}

According to the inclusion criteria, we analysed data of the seventy five patients who were suffering from ESRD and were on haemodialysis.

\section{Demographic profile}

Out of the 75 patients, majority $(82 \%)$ of the patients were male and $18 \%$ were female. And nearly two-third $(61.33 \%)$ of the patients were in the age group of 41-60 years, $22.7 \%$ were over the age of 60 and $16 \%$ of the patients were in the age group 18-40 (Figure 1).

\section{Pre-and post-haemodialysis laboratory reports status}

There was not much weight reduction after haemodialysis. Serum albumin, serum sodium and blood haemoglobin levels level were almost unchanged in post - haemodialysis state. While blood urea, serum creatinine, phosphorous, potassium levels were reduced significantly after haemodialysis, and serum calcium level was increased significantly after haemodialysis (Table 1 ).

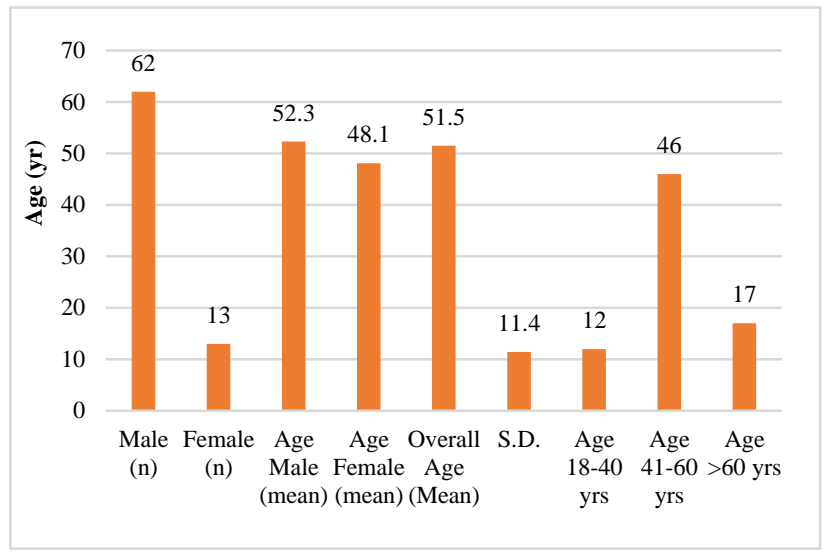

Figure 1: Distribution of age and gender of the ESRD patients.

Table 1: Pre and post-haemodialysis laboratory reports.

\begin{tabular}{|c|c|c|c|c|c|c|c|c|c|}
\hline & $\begin{array}{l}\text { Weight } \\
\text { Kgs }\end{array}$ & $\begin{array}{l}\text { Albumin } \\
\text { (g/dl) }\end{array}$ & $\begin{array}{l}\text { Urea } \\
\text { (mg/dl) }\end{array}$ & $\begin{array}{l}\text { Creatinine } \\
\text { (mg/dl) }\end{array}$ & $\begin{array}{l}\text { Calcium } \\
\text { (mg/dl) }\end{array}$ & $\begin{array}{l}\text { Phosphorous } \\
\text { (mg/dl) }\end{array}$ & $\begin{array}{l}\text { Potassium } \\
(\mathbf{m m o l} / \mathbf{d l})\end{array}$ & $\begin{array}{l}\text { Sodium } \\
(\mathbf{m m o l} / \mathbf{d l})\end{array}$ & $\begin{array}{l}\text { Hb } \\
\text { (g/dl) }\end{array}$ \\
\hline $\begin{array}{l}\text { Pre - } \\
\text { haemodialysis } \\
\text { mean (S.D.) }\end{array}$ & $\begin{array}{l}59.57 \\
(10.97)\end{array}$ & $\begin{array}{l}3.5 \\
(0.5)\end{array}$ & $\begin{array}{l}98.5 \\
(30.3)\end{array}$ & $\begin{array}{l}8.9 \\
(2.7)\end{array}$ & $\begin{array}{l}8.5 \\
(1.0)\end{array}$ & $\begin{array}{l}4.6 \\
(1.3)\end{array}$ & $\begin{array}{l}5.1 \\
(1.0)\end{array}$ & $\begin{array}{r}137.1 \\
(5.2)\end{array}$ & $\begin{array}{l}7.3 \\
(1.6)\end{array}$ \\
\hline $\begin{array}{l}\text { Post- } \\
\text { haemodialysis } \\
\text { mean (S.D.) }\end{array}$ & $\begin{array}{l}57.1 \\
(10.94)\end{array}$ & $\begin{array}{l}3.6 \\
(0.6)\end{array}$ & $\begin{array}{l}43.1 \\
(23.8)\end{array}$ & $\begin{array}{l}4.8 \\
(2.6)\end{array}$ & $\begin{array}{l}9.4 \\
(1.4)\end{array}$ & $\begin{array}{l}3.5 \\
(1.3)\end{array}$ & $\begin{array}{l}3.9 \\
(1.2)\end{array}$ & $\begin{array}{l}137.5 \\
(4.7)\end{array}$ & $\begin{array}{l}7.9 \\
(1.8)\end{array}$ \\
\hline $\begin{array}{l}\text { P value (two - } \\
\text { tailed) }\end{array}$ & 0.17 & 0.27 & 0.0001 & 0.0001 & 0.0001 & 0.0001 & 0.0001 & 0.6 & 0.03 \\
\hline
\end{tabular}

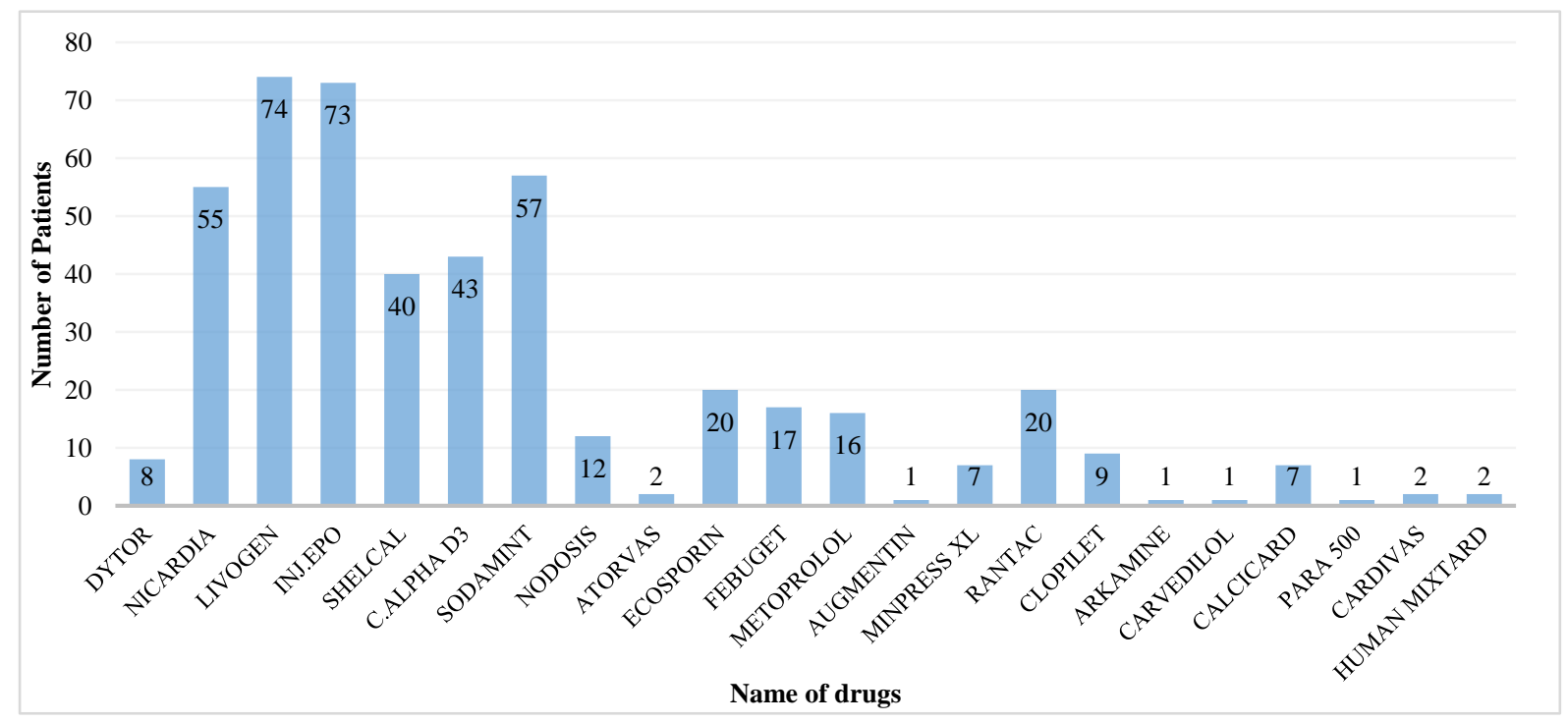

Figure 2: Number of ESRD patient used drug. 


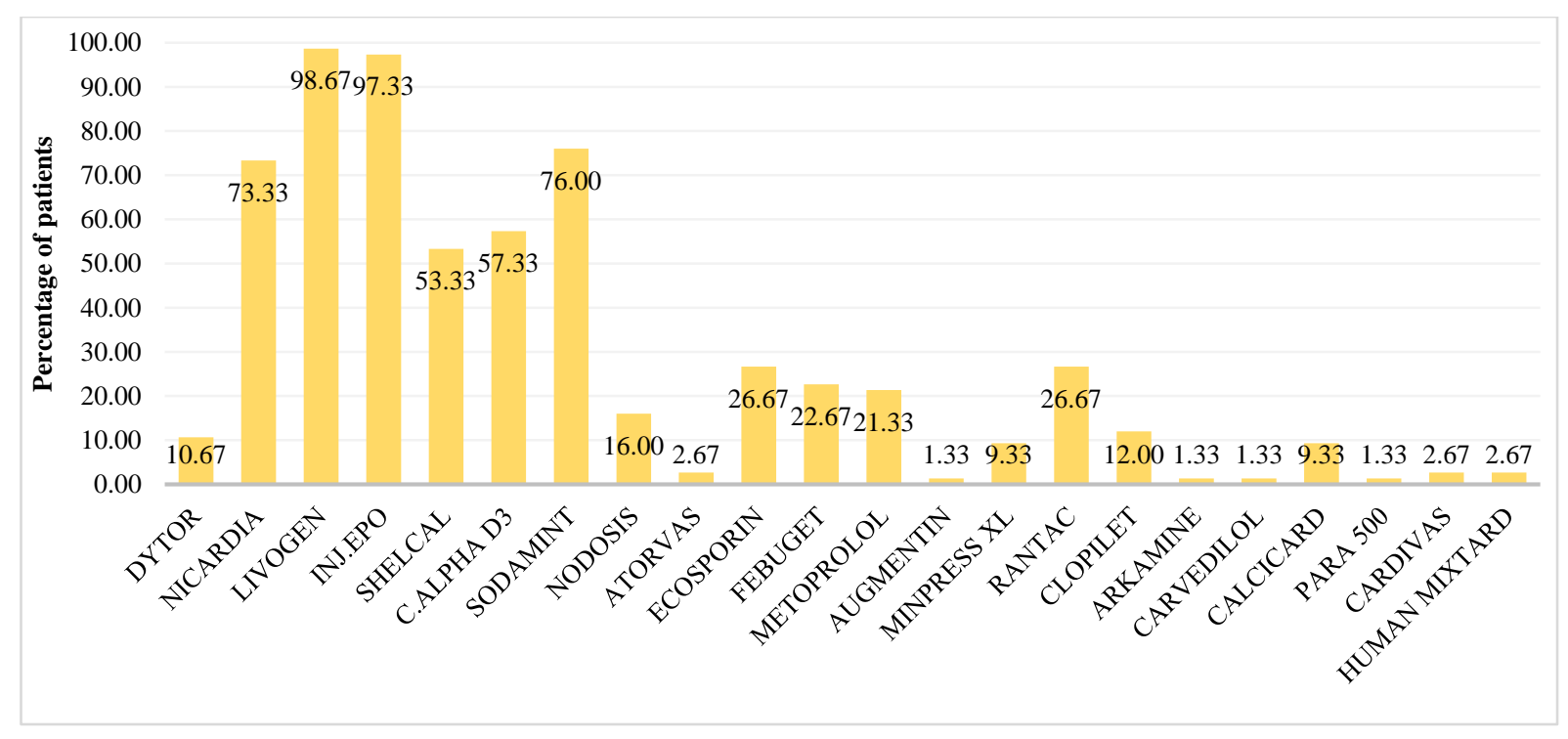

Figure 3: Percent-wise drugs prescribed to the ESRD patients.

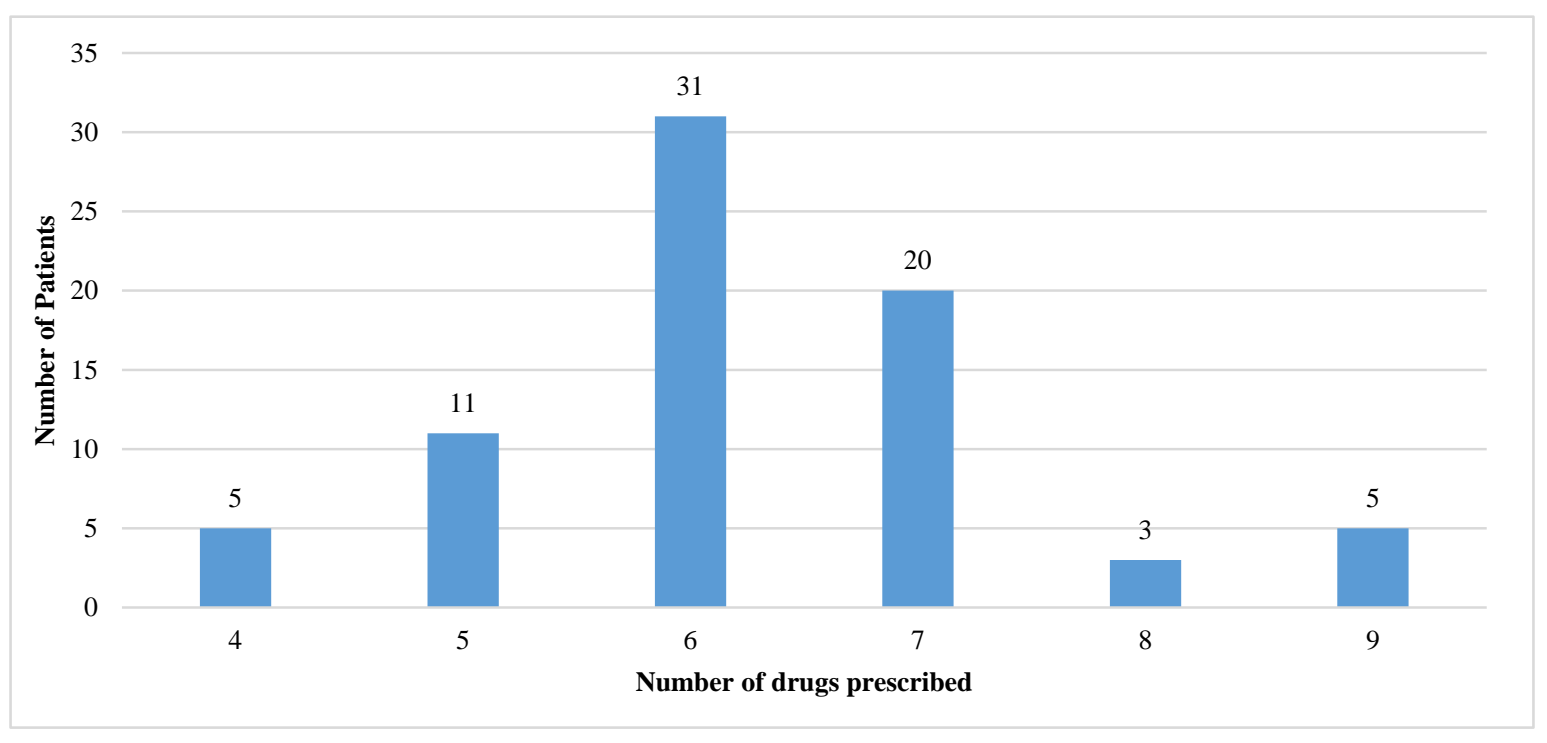

Figure 4: Number of drugs prescribed to the ESRD patients.

\section{Drugs prescribing pattern in ESRD patients}

Out of 75 ESRD patients, almost all patients 74 (98.7\%) were given tablet Livogen (ingredient ferrous fumarate and folic acid), 73 (97.3\%) patients given Inj. EPO (Erythropoietin), 55 (73.3\%) tab. Nicardia (nifedipine), 54 (76\%) tab. Sodamint (Sodium bicarbonate), 43 (57.3\%) capsule Alpha D3 (1, 25 Dihydroxycholecalciferol), 40 (53.3\%) tab. Shelcal (calcium) (Figure 2 and 3).

While, out of 75 ESRD patients, between 12 (16\%) to 20 (26\%) patients were prescribed tab. Nodosis (sodium bicarbonate), tab. metoprolol, tab. Febuget (febuxostat), tab. Ecosprin (aspirin), and tab. Rantac (ranitidine).

Only $1(1.3 \%)$ to 9 (12\%) patients received tablet Augmentin (amoxicillin), tab. Arkamine (clonidine), tab.
Carvedilol, tab. Para 500 (Paracetamol 500), tab. Atorvas (atorvastatin), Human mixtard (insulin), tab. Calcicard (nifedipine), tab. Minipress XL (prazosin), tab. Dytor (torsemide), and tab. Clopilet (aspirin+clopidogrel).

Each patient was prescribed drugs with an average of six in numbers. Around $78 \%$ of them were prescribed 6 or more drugs (Figure 4).

\section{DISCUSSION}

ESRD is the stage $\mathrm{V}$ of chronic kidney disease, that is, the kidneys are functioning at less than $15 \%$ of their normal capacity. The imbalances of biochemical parameters of the blood are almost restored significantly by haemodialysis. 
In the present study, blood urea, serum creatinine, phosphorous, potassium levels were reduced significantly in post haemodialysis condition. In ESRD patients the glomerular filtration rate is less than $15 \mathrm{ml} /$ minute. And this causes the blood urea and creatinine levels to increase. Sarhat et al showed in his study, that there was a significant decrease in the blood urea and creatinine level after the haemodialysis which was high in pre haemodialysis condition in both control and test group. ${ }^{5}$

There was no much weight reduction after haemodialysis. Serum albumin, serum sodium and blood haemoglobin levels were almost unchanged in post-haemodialysis state.

There was no significant difference between the pre- and post-haemodialysis parameters- serum $\mathrm{Na}^{+}$, serum albumin and blood hemoglobulin.

Pharmacotherapy of ESRD is complex and inevitably requires poly-pharmacy with frequent monitoring of drugs and their dosage adjustments. Polypharmacy is defined as prescription of five or more medications to one patient at one time. ${ }^{6}$ Polypharmacy is inevitable in treating end stage renal disease as it mostly is accompanied by a combination of many co-morbid conditions like hypertension, anaemia, mineral bone disorders, diabetes, ulcers etc.

In the present study, out of 75 ESRD patients, almost all patients $74(98.7 \%)$ prescribed tablet Livogen (ingredient: ferrous fumarate and folic acid), 73 (97.3\%) patients given Inj. EPO (Erythropoietin), 55 (73.3\%) tab. Nicardia (nifedipine), $54 \quad(76 \%)$ tab. Sodamint (sodium bicarbonate), $43(57.3 \%)$ capsule Alpha D3 (1, 25 dihydroxy-cholecalciferol), $40 \quad(53.3 \%)$ tab. Shelcal (Calcium).

While, out of 75 ESRD patients, between 12 (16\%) to 20 (26\%) patients prescribed tab. Nodosis (sodium bicarbonate), tab. Metoprolol, tab. Febuget (febuxostat), tab. Ecosprin (aspirin), and tab. Rantac (ranitidine).

Only $1(1.3 \%)$ to $9(12 \%)$ patients received tablet Augmentin (amoxicillin), tab. Arkamine (clonidine), tab. Carvedilol, tab. Para 500 (paracetamol 500), tab. Atorvas (atorvastatin), Human mixtard (insulin), tab. Calcicard (nifedipine), tab. Minipress XL (prazosin), tab. Dytor (torsemide), and tab. Clopilet (aspirin+clopidogrel).

Many previous researches like, Safar, Michel, et al, Singh, Szczech et al, Parikh, Hwang et al, Tamilselvan, veerapandiyan et al, Yusuf, Howell et al, $\mathrm{Xu}$, et al were also reported in their individual studies that, poly pharmacy is essential but complex to treat the ESRD with co-morbid conditions to get best outcome. ${ }^{7-10}$

In this study the male subjects predominated (82.6\%) like any other study conducted previously on kidney disease. Majority $(61.3 \%)$ of the patients were in the age group of 40-60 years.

\section{CONCLUSION}

To achieve the normal physiological status of the patients who are suffering from ESRD, very challenging task to the healthcare professionals, especially nephrologist. In the present study, all the ESRD patients were on the more than 6 number of medications, and haemodialysis also, to control the blood pressure, reduce volume of body fluid, reduce risk of anaemia, reduce risk of hyperkalaemia, supplement the calcium loss, and simultaneously reduced acidotic conditions by giving sodium bicarbonates as per the clinical needs to the patients, reduced complications of associated with the cardiovascular pathology and diabetes mellitus. The available two models of treatment, i.e., haemodialysis and poly-pharmacy at hospital setup to face the challenges associated with the ESRD, and even outcome after application of both these two models of therapies did not provide optimal normal healthy life status to ESRD.

\section{Limitation of the study}

Since, to justify the achievement of the decided objectives in this present study was based on the obtained data from the Patients case-sheet and haemodialysis register without direct communication from the patients. Since, as a MBBS $2^{\text {nd }}$ professional students, I have no authority to involve life - threatening procedure for the haemodialysis and I don't have competency to advice medication to the ESRD patients. So, the limitation of this study is based on the patient's records only.

\section{ACKNOWLEDGEMENTS}

We would like to acknowledge, the Head of the Department of Nephrology to given permission to record the data. As a principal investigator, I would like to acknowledge hearty to Dr. Surendra Kumar Bouddh MD, Professor Head, Department of Pharmacology, who wrote this full manuscript, did statistical calculations and arranged the obtained observations in bar-charts. This is a Short Term Studentship (STS) original research work has been selected by the Indian Council for Medical Research (ICMR), New Delhi, India for the academic year 20172018, and its Project Code No. is 2018-05873.

Funding: No funding sources

Conflict of interest: None declared

Ethical approval: The study was approved by the Institutional Ethics Committee from the DSMCH

\section{REFERENCES}

1. Coresh J, Astor BC, Greene T, Eknoyan G, Levey AS. Prevalence of chronic kidney disease and decreased kidney function in the adult US Population: Third National Health and Nutrition Examination Survey. Am J Kidney Dis. 2003;41:112 . 
2. Singh AK, Farag YMK, Mittal BV, Subramanian KK, Reddy SRK, Acharya VN, et al. Epidemiology and risk factors of chronic kidney disease in India results from the SEEK (Screening and Early Evaluation of Kidney disease) study. BMC Nephrol. 2013;14:114.

3. Chawla S, Ranjan A, Singh NP, Garg N, Kumar A. Assessment of drug utilization and quality of life in Patients of chronic kidney disease in a tertiary care Hospital. World J Pharmacy Pharm Sci. 2016;5(9):1214-26.

4. Shah J, Khakhkhar T, Bhirud S, Shah RB, Date S. Study of utilization pattern of anti-hypertensive drugs in hypertensive diabetic patients with or without reduced renal function at tertiary care teaching hospital. Int J Med Sci Public Health. 2013;2:175-80.

5. Sarhat E, Murtadha NA. Biochemical Changes in Chronic Renal Failure Pre and Post Hemodialysis. J Environ Sci Engineering. 2016;5:190-5.

6. Safar Michel E. Central pulse pressure and mortality in end-stage renal disease. Hypertension. 2002;39(3):735-8.

7. El-Kishawi, El-Nahas. Renal Osteodystrophy: Review of the Disease and its Treatment. Saudi J Kid Dis Transplant. 2006;17(3):373-82.
8. Parikh NI, Hwang SJ, Larson MG, Meigs JB, Levy D, Fox CS. Cardiovascular disease risk factors in chronic kidney disease: overall burden and rates of treatment and control. Arch Intern Med. 2006;166:1884-91.

9. Tamilselvan T, Veerapandiyan AK, Karthik N. Study on drug utilization pattern of chronic renal failure patients in a tertiary care hospital. Int J Pharm Pharm Sci. 204;6(9):482-4.

10. Amin N, Mahmood RT, Asad MJ, Zafar M, Raja AM. Evaluating Urea and Creatinine Levels in Chronic Renal Failure Pre and Post Dialysis: A Prospective Study. J Cardiovascular Dis. 2014;2(2):1-4.

Cite this article as: Gokulraj SP, Bouddh SK, Rajesh J. Drug utilization pattern and selected biochemical parameters in pre- and post-hemodialysis state in the end stage renal disease patients: a cross sectional study at a tertiary care hospital. Int J Basic Clin Pharmacol 2019;8:2074-9. 